\title{
Factors Associated with Quality of Life and Glycemic Control in Diabetes Mellitus Type 2 Patients in Sangkha Hospital, Surin Province, Thailand
}

\author{
Panistaporn Khanthaboon ${ }^{1}$, Tanapron Kumbudda', Pinmanee Poonsuk ${ }^{2}$, Chatmanee Taengthonglang ${ }^{2}$, Kritsanee Saramunee ${ }^{1}$, \\ Wiraphol Phimarn ${ }^{1 *}$ \\ ${ }^{1}$ Faculty of Pharmacy, Mahasarakham University, Mahasarakham, THAILAND. \\ ${ }^{2}$ Pharmacist, Pharmacy Department, Sangkha Hospital, Surin, THAILAND.
}

\begin{abstract}
Objectives: This study aimed to measure (1) quality of life (QOL) and utility in diabetes mellitus (DM) type 2 patients (2) factors associated the quality of life and (3) factors associated the glycemic control. Methods: This study was a cross-sectional study. Samples were DM type 2 patients who attended diabetic outpatient clinic at Sangkha Hospital, Surin province between November 2017 and January 2018. QOL was prospectively assessed using the EQ-5D-5L questionnaire. Data was analyzed by descriptive and binary logistic regression. Results: The DM type 2 patients $(n=158)$ were included in this study. The participants had an average $\mathrm{QOL}$ score in a high level. There were no factors associated with $\mathrm{QOL}$. The factors associated with glycemic control were education level $(\mathrm{OR}=2.85 ; 95 \% \mathrm{Cl}$ : $1.17-6.98)$ and insulin therapy (OR=3.04; $95 \% \mathrm{Cl}: 1.10-8.35)$. Conclusion: There
\end{abstract}

were no factors associated with QOL. Only education level and insulin therapy factors were associated with glycemic control.

Key words: Diabetes Mellitus, Quality of life, Glycemic control, Factors, EQ-5D-5L.

\section{Correspondence}

Dr. Wiraphol Phimarn,

Social Pharmacy Research Unit, Faculty of Pharmacy, Mahasarakham University, Mahasarakham-44150, THAILAND.

Phone: +66 43754360

Email: wiraphol.p@msu.ac.th

DOI: 10.5530/jyp.2020.12.30

\section{INTRODUCTION}

Diabetes Mellitus (DM) is a chronic disease which is an important public health problem. ${ }^{1}$ The number of DM patients continues to rise, with a global prevalence of 422 million people reported in 2014. ${ }^{2}$ The World Health Organization (WHO) predicted that the number of DM patients would increase to 592 million people by $2035 .{ }^{3}$ Survey data in Thailand found in 2015, that 4.0 million Thai people were diabetic, with estimated 2.1 million being undiagnosed. ${ }^{4}$ More than $75 \%$ of diabetic patients who have DM for more than 20 years will develop macro and microvascular complications. ${ }^{5}$ Moreover, DM has impact on quality of life (QOL). ${ }^{6}$ QOL is the general well-being of individuals and outlining negative and positive feature of life. ${ }^{7}$ The several studies suggest that DM patients may suffer from health complications such as cardiovascular disease, kidney disease and retinopathy. Previous studies have demonstrated uncontrolled blood glucose levels associated cardiovascular and renal diseases. Moreover, DM patients with poor glycemic control had more depression and low QOL. ${ }^{8}$

Previous studies ${ }^{6}$ reported that many factors in DM patients had affected their health and QOL. Therefore, this study aimed to investigate the factors associated with QOL and glycemic control in Thai diabetics.

\section{MATERIALS AND METHODS}

\section{Study design}

This study was cross sectional study. We conducted the study between November 2017 and January 2018 at a diabetic outpatient clinic in Sangkha, Surin province. The study was approved by the Mahasarakham University Ethics Committee for research Involving Human subjects
(No 002/2017). All participants gave written informed consent before participating in the study.

\section{Sample size calculation}

The sample size was calculated by the formula

$$
\mathrm{n}=\frac{\mathrm{NZ}_{\frac{\alpha}{2}}^{2} \mathrm{p}(1-\mathrm{p})}{\mathrm{e}^{2}(\mathrm{~N}-1)+\mathrm{Z}_{\frac{\alpha}{2}}^{2} \mathrm{p}(1-\mathrm{p})}
$$

$\mathrm{n}=$ minimum number of patients needed for the study; $\mathrm{N}=$ total number of diabetic patients in the clinic; $\mathrm{Z}_{\frac{\alpha}{2}}=1.96$ at $\alpha=0.05, p=0.22$. The minimum number needed in this study was determined to be 158 .

Inclusion criteria were as follows: (1) 18 years of age or older; (2) DM type 2 patients and (3) completing questionnaire by themselves. Patient personal information was kept confidential.

Exclusion criteria was patients who cannot monitor laboratory data.

\section{Data collections}

1. Structured questionnaires collected patient's medical records (type of diabetes, diabetic duration, DM complication, ant diabetics and other medication) and laboratory data (fasting plasma glucose level and $\mathrm{HbA1C}$ level). All subjects were interviewed for their monthly income, occupation, education level and other health behaviors.

2. EQ-5D-5L questionnaire was used to measure QOL. This questionnaire consisted two parts: the first part consists of five 
dimensions of health: movement, self-care, regular activities (such as work, study, home, family activities), pain/discomfort. Thereafter, the EQ-5D-5L score will be calculated as a utility by The Health Intervention and Technology Assessment Program (HITAP) formula. The utility is a score that reflects the preference of a person regarding their health. The score ranges from 0 to 1 , with 0 meaning death and 1 meaning complete health. The utility score can calculate by the formula: 1-coefficient of each health dimension. ${ }^{9}$

\section{Statistical analysis}

The software program SPSS version 16.0 was used for analyses. Descriptive statistics reported were mean, standard deviation and percentage as appropriate. Statistical differences within the same group were tested using paired t-tests while an independent $t$-test was used for testing the differences between two groups. The level of statistical significance was determined to be 0.05 or less. Multiple logistic regression was used to determine factors associated with QOL, FBS and $\mathrm{HbA}_{1 \mathrm{C}}$ level.

\section{RESULTS}

\section{Baseline characteristics}

Most DM cases were female, in middle age, who had less than high school education. Seventy-nine percent of the subjects were married, $59 \%$ were agriculturist. The average of DM duration was $8.04 \pm 6.80$ years. Based on latest laboratory results, the average $\mathrm{FBS}$ and $\mathrm{HbA}_{1 \mathrm{C}}$ levels were 182.34 $\pm 83.35 \mathrm{mg} / \mathrm{dL}$ and $7.76 \pm 1.74$, respectively. 27.8 percent of participants had hypertension and hyperlipidemia as co-diseases. Moreover, $79.1 \%$ of the cases used oral hypoglycemic agents. The majority of people $(>80 \%)$ have never consumed alcohol and were non-smokers (Table 1).

\section{Quality of life and utility}

QOL was determined from the EQ-5D-5L questionnaire. This questionnaire was divided into five dimensions; (1) mobility (2) self-care (3) usual activities (e.g. work, study, housework, family or leisure activities) (4) pain/discomfort and (5) anxiety/depression. Each dimension was divided into 5 health state levels graded from level 1 which indicated having no problem, to level 5 which indicated extreme problems. The average QOL score was $1.33 \pm 0.66$ in the mobility dimension, $1.09 \pm 0.32$ in the self-care dimension, $1.12 \pm 0.35$ in the usual activities dimension, $2.18 \pm 1.12$ in the pain/discomfort dimension and $1.77 \pm 0.97$ in the anxiety/depression dimension. This study found the average utility score was $0.87 \pm 0.15$.

\section{Factors associated with utility}

Utility is a score that reflects the preference of a person regarding their health. The score ranges from 0 to 1 , with 0 meaning death and 1 meaning complete health. This study considered that a utility score $\geq 0.8$ means a good quality of life. The logistic regression analysis demonstrated that there were no factors associated with utility. (Table 2)

\section{Factors associated with glycemic control}

Factors associated with the $\mathrm{HbA}_{1 \mathrm{C}}$ control are shown in Table 3 . $\mathrm{HbA}_{1 \mathrm{C}}$ control as defined by the American diabetes association $2018^{10}$ was an optimal goal of $\mathrm{HbA} 1 \mathrm{C}<7.0 \%$. Diabetic participants with secondary school completed or more were 2.85 time more likely to control $\mathrm{HbA}_{1 \mathrm{C}}$ than those with an education level $\leq$ primary school $(\mathrm{OR}=2.85 ; 95 \%$ $\mathrm{CI}=1.17-6.98)$.

Patients with insulin therapy controlled their HbA1C level better than other groups $(\mathrm{OR}=3.04 ; 95 \% \mathrm{Cl}=1.10-8.35 ; p=0.031)$.
Table 1: Baseline characteristic of participants ( $N=158)$.

\begin{tabular}{|c|c|}
\hline Characteristics & $N(\%)(n=158)$ \\
\hline Female & $115(72.80)$ \\
\hline Average age $($ year $)($ Mean \pm SD) & $57.25 \pm 10.23$ \\
\hline \multicolumn{2}{|l|}{ Marital status } \\
\hline Single & $12(7.60)$ \\
\hline Married & $124(78.50)$ \\
\hline Separate/Widow & $22(13.90)$ \\
\hline \multicolumn{2}{|l|}{ Education } \\
\hline No schooling & $18(11.40)$ \\
\hline Primary school & $111(70.30)$ \\
\hline Secondary school & $21(13.30)$ \\
\hline Bachelor degree & $8(5.00)$ \\
\hline \multicolumn{2}{|l|}{ Occupation } \\
\hline Agriculture worker & $93(58.90)$ \\
\hline Merchant & $20(12.70)$ \\
\hline Government officer & $9(5.70)$ \\
\hline Others & $23(14.60)$ \\
\hline $\mathrm{DM}$ duration since diagnosis(years)(Mean $\pm \mathrm{SD})$ & $8.04 \pm 6.80$ \\
\hline FBS level $(\mathrm{mg} \%)($ Mean \pm SD) & $182.34 \pm 83.35$ \\
\hline $\mathrm{HbA1}_{c}(\%)($ Mean $\pm \mathrm{SD})$ & $7.76 \pm 1.74$ \\
\hline \multicolumn{2}{|l|}{ Co-morbidity } \\
\hline No & $48(30.40)$ \\
\hline Hypertension & $30(19.00)$ \\
\hline Hyperlipidemia & $12(7.60)$ \\
\hline Hypertension and hyperlipidemia & $44(27.80)$ \\
\hline \multicolumn{2}{|l|}{ Insulin therapy } \\
\hline Yes & $33(20.90)$ \\
\hline No & $125(79.10)$ \\
\hline \multicolumn{2}{|l|}{ Smoking } \\
\hline Yes & $15(9.50)$ \\
\hline No & $143(90.50)$ \\
\hline \multicolumn{2}{|l|}{ Alcohol consumption } \\
\hline Yes & $27(17.10)$ \\
\hline No & $131(82.90)$ \\
\hline
\end{tabular}

\section{DISCUSSION}

Seventy-two percent of the participants were female, average age was $57.25 \pm 10.23$ years and most of them were married. More than half of them $(70.3 \%)$ had completed primary school education and $58.9 \%$ of them were agriculturist. The average duration of patients with DM was $8.04 \pm 6.80$ years. Thirty percent of them had no underlying disease and around $28 \%$ had hypertension and hyperlipidemia. This study found that $20.9 \%$ were being treated with insulin.

In this study, quality of life levels were categorized into low or high domains. The majority of the participants had a high quality of life. Several studies conducted in different areas have reported quality of life among DM patients. Brown et al. (2004) ${ }^{11}$ found the QOL among DM population in India was low. Previous studies ${ }^{12,13}$ demonstrated that the QOL participant were experiencing a moderate level of QOL. However, 
Table 2 : Association of variables with utility score among study subjects.

\begin{tabular}{|c|c|c|c|c|}
\hline \multirow{2}{*}{$\begin{array}{l}\text { Variables } \\
\quad<0.8\end{array}$} & \multicolumn{2}{|c|}{ Utility Score } & \multirow{2}{*}{$\begin{array}{l}\text { Adjusted OR } \\
\qquad(95 \% \mathrm{Cl})\end{array}$} & \multirow[t]{2}{*}{$p$-value } \\
\hline & $\geq 0.8$ & & & \\
\hline \multicolumn{5}{|c|}{ DM duration since diagnosis } \\
\hline$<5$ years & $13(35.10 \%)$ & $52(43.00 \%)$ & 1 & 0.511 \\
\hline$\geq 5$ years & $24(64.90 \%)$ & $69(57.00 \%)$ & $0.76(0.33-1.74)$ & \\
\hline & & FBS level & & \\
\hline$\leq 130 \mathrm{mg} / \mathrm{dL}$ & $10(27.00 \%)$ & $32(26.40 \%)$ & 1 & 0.892 \\
\hline$>130 \mathrm{mg} / \mathrm{dL}$ & $27(73.00 \%)$ & $89(73.60 \%)$ & $1.07(0.43-2.66)$ & \\
\hline & & $\mathrm{HbA}_{1 \mathrm{c}}$ level & & \\
\hline$<7 \%$ & $13(35.10 \%)$ & $48(40.50 \%)$ & 1 & 0.699 \\
\hline$\geq 7 \%$ & $24(64.90 \%)$ & $73(59.50 \%)$ & $0.84(0.35-2.01)$ & \\
\hline \multicolumn{5}{|c|}{ Co-morbidity } \\
\hline Yes & $26(70.20 \%)$ & $83(68.60 \%)$ & 1 & 0.790 \\
\hline No & $11(29.80 \%)$ & $38(31.40 \%)$ & $0.89(0.36-2.18)$ & \\
\hline \multicolumn{5}{|c|}{ Insulin therapy } \\
\hline Yes & $11(29.70 \%)$ & $23(19.00 \%)$ & 1 & 0.377 \\
\hline No & $26(70.30 \%)$ & 98 (81.00\%) & $1.50(0.61-3.69)$ & \\
\hline \multicolumn{5}{|c|}{ Monthly income } \\
\hline $\begin{array}{l}<5,000 \\
\text { Thai Baht }\end{array}$ & $28(75.70 \%)$ & $82(67.80 \%)$ & 1 & 0.482 \\
\hline $\begin{array}{l}\geq 5,000 \\
\text { Thai Baht }\end{array}$ & $9(24.30 \%)$ & $39(32.20 \%)$ & $1.37(0.57-3.27)$ & \\
\hline \multicolumn{5}{|c|}{ Number of medication used } \\
\hline$<5$ items & $8(21.60 \%)$ & $25(20.70 \%)$ & 1 & 0.874 \\
\hline$\geq 5$ items & $29(78.40 \%)$ & $96(79.30 \%)$ & $1.09(0.38-3.08)$ & \\
\hline
\end{tabular}

Table 3 : Association of variables with $\mathrm{HbA}_{1 \mathrm{c}}$ control among study subjects.

\begin{tabular}{|c|c|c|c|c|}
\hline \multirow[t]{2}{*}{ Variables } & \multicolumn{2}{|c|}{$\mathrm{HbA}_{1 \mathrm{c}}$ level } & \multirow{2}{*}{$\begin{array}{l}\text { Adjusted OR } \\
\qquad(95 \% \mathrm{Cl})\end{array}$} & \multirow[t]{2}{*}{$p$-value } \\
\hline & $<7 \%$ & $\geq 7 \%$ & & \\
\hline \multicolumn{5}{|c|}{ Education } \\
\hline $\begin{array}{c}\leq \text { Primary } \\
\text { school }\end{array}$ & $46(75.40 \%)$ & $83(85.60 \%)$ & 1 & $0.022^{*}$ \\
\hline $\begin{array}{c}>\text { Secondary } \\
\text { school }\end{array}$ & $15(24.60 \%)$ & $14(14.40 \%)$ & $2.85\left(1.17-6.98^{\star}\right)$ & \\
\hline \multicolumn{5}{|c|}{ DM duration since diagnosis } \\
\hline$<5$ years & $47(73.40 \%)$ & $56(59.60 \%)$ & 1 & 0.067 \\
\hline$\geq 5$ years & $17(26.60 \%)$ & $38(40.40 \%)$ & $1.93(0.96-3.90)$ & \\
\hline \multicolumn{5}{|c|}{ Co-morbidity } \\
\hline Yes & $43(70.50 \%)$ & $67(69.10 \%)$ & 1 & 0.989 \\
\hline No & $18(29.50 \%)$ & $30(30.90 \%)$ & $1.01(0.46-2.21)$ & \\
\hline \multicolumn{5}{|c|}{ Insulin therapy } \\
\hline Yes & $6(9.80 \%)$ & $27(27.80 \%)$ & 1 & $0.031^{*}$ \\
\hline No & $55(90.20 \%)$ & $70(72.20 \%)$ & $3.04\left(1.10-8.35^{*}\right)$ & \\
\hline \multicolumn{5}{|c|}{ Alcohol consumption } \\
\hline Yes & $14(23.00 \%)$ & $13(13.40 \%)$ & 1 & 0.245 \\
\hline No & $47(77.00 \%)$ & $84(86.60 \%)$ & $0.58(0.23-1.46)$ & \\
\hline \multicolumn{5}{|c|}{ Number of medication used } \\
\hline$<5$ items & $19(31.10 \%)$ & $13(13.40 \%)$ & 1 & 0.545 \\
\hline$\geq 5$ items & $42(68.90 \%)$ & $84(86.60 \%)$ & $1.28(0.58-2.85)$ & \\
\hline
\end{tabular}

this result is similar to previous QOL studies conducted in Thailand ${ }^{14}$ which revealed a high level of QOL among the population with DM. A possible reason for similar finding in previous studies may be due to cultural and lifestyle similarities and the other countries might have differed due to dissimilarities in culture, lifestyle and other social aspect of life.

In our study, there were no factors associated with utility score. This finding contradict with several previous studies. ${ }^{16-18}$ The previous studies found relationships between several factors such as comorbidities and low incomes and low utility score. ${ }^{16}$

After factors were controlled using multiple logistic regression only two factors were seen to be associated with $\mathrm{HbA}_{1 \mathrm{C}}$ control; an education level higher than secondary school and treatment with insulin therapy. Previous studies have found participants whose higher level of education had $\mathrm{HbA}_{1 \mathrm{C}}$ levels lower than the low level of education. ${ }^{19}$ The low educational level may influence adherence to medication used and also diet control. ${ }^{20}$ Moreover, patients with a higher education level may encourage the pursuit knowledge and these factors may lead to performance of proper self-management and ability to control $\mathrm{HbA}_{1 \mathrm{C}}$ levels better than people with a low level of education. ${ }^{21,22}$

Patients treated with non-insulin were found to be significantly associated with poor $\mathrm{HbA}_{1 \mathrm{C}}$ control. This result is not surprising because DM patients treated with insulin were patients with high blood glucose level and cannot control blood glucose level with oral ant diabetic drugs. ${ }^{10}$

Our study found no relationship between several factors of DM duration since diagnosis, co-morbidity and number of medication used and $\mathrm{HbA}_{1 \mathrm{C}}$ level. The Verma $(2008)^{13}$ study demonstrated poor glycemic control related diabetes duration. This may have been caused by diabetes being a chronic disease. DM patients have to use blood glucose lowering agent(s) continuously for a long time. This may influence DM patients to develop fatigue to treatments.

A previous study ${ }^{23}$ showed poor control of DM is related to co-morbidity and one or more oral medication agent(s) used. However, this study found these factors did not relate to blood glucose control. A possible reason for this may be the small number of participants included in this study. These factors are important to note and several studies suggest that longer duration of diabetes is associated with more complications and more difficulty in maintaining glycemic control. ${ }^{24,25}$

This study had some limitations due to it being performed in only one hospital with a small number of DM patients and short duration. Therefore, future research should be performed in a larger DM population in a different study area to obtain more data on factors that influence QOL and glycemic control.

\section{CONCLUSION}

This study was conducted among 158 participants diagnosed with DM type 2. Analysis of the level of QOL showed the average QOL score was 'high'. However, there were no factors associated with QOL. In terms of glycemic control, there are only education level and insulin therapy factors associated with glycemic control.

\section{ACKNOWLEDGEMENT}

We acknowledge all the DM participants of this study. The authors wish to thank Dr. Adrian Roderick Plant for language editorial assistance.

\section{CONFLICT OF INTEREST}

The authors declare no conflict of interests.

\section{ABBREVIATIONS}

DM: Diabetes mellitus; QOL: quality of life; FBS: Fasting blood sugar; OR: Odds ratio. 


\section{SUMMARY}

Based on current evidence, there were no factors associated with QOL and only two factors associated with glycemic control in Thai DM patients.

\section{REFERENCES}

1. Al-Lawati JA. Diabetes Mellitus: A Local and Global Public Health Emergency Oman Med J. 2017:32(3):177-9.

2. World Health Organization (WHO). Global report on diabetes. 2018. [cited 2 Mar 2020] Available from : https://apps.who.int/iris/bitstream/handle/10665/ 204871/9789241565257_eng.pdf;jsessionid=BC290CEAED45DB66FE5D15B8 $1 \mathrm{E} 59208 \mathrm{~F}$ ? sequence $=1$.

3. Guariguata L, Whiting DR, Hambleton I, Beagley J, Linnenkamp U, Shaw JE. Global estimates of diabetes prevalence for 2013 and projections for 2035. Diabetes Res Clin Pract. 2014;103(2):137-49

4. Aekplakorn W, Chariyalertsak $S$, Kessomboon $P$, Assanangkornchai $S$, Taneepanichskul S, Putwatana P. Prevalence of Diabetes and Relationship with Socioeconomic Status in the Thai Population: National Health Examination Survey, 2004-2014. J Diabetes Res. 2018;1654530. doi: 10.1155/2018/1654530. eCollection 2018.

5. Chawla A, Chawla R, Jaggi S. Microvasular and macrovascular complications in diabetes mellitus: Distinct or continuum?. Indian J Endocrinol Metab. 2016;20(4):546-51.

6. Fujita B, Lauten A, Goebel B, Franz M, Fritzenwanger M, Ferrari M, et al. Impact of diabetes mellitus on quality of life in patients with congestive heart failure. Qual Life Res. 2012;21(7):1171-6.

7. Post MWM. Definitions of Quality of Life: What Has Happened and How to Move On. Top Spinal Cord Inj Rehabil. 2014;20(3):167-80.

8. Trikkalinou A, Papazafiropoulou AK, Melidonis A. Type 2 diabetes and quality of life. World J Diabetes. 2017;8(4):120-9.

9. Pattanaphesaj J. Health-related quality of life measure (EQ-5D-5L): Measurement property testing and its preference-based score in Thai population [Doctoral dissertation]. Mahidol University. 2014.

10. American Diabetes Association (ADA). Professional Practice Committee: Standards of Medical Care in Diabetes-2018. Diabetes Care. 2018;41(Suppl 1):S3. https://doi.org/10.2337/dc18-SPPC01

11. Brown DW, Balluz LS, Giles WH, Beckles GL, Moriarty DG, Ford ES, et al Diabetes mellitus and health-related quality of life among older adults. Findings from the behavioral risk factor surveillance system (BRFSS). Diabetes Res Clin Pract. 2004;65(2):105-15.
12. Polonsky WH anderson BJ, Lohrer PA, Welch G, Jacobson AM, Aponte JE, et al. Assessment of Diabetes-Related Distress. Diabetes Care. 1995;18(6):754-60.

13. Varma GR, Kusuma YS, Babu BV. Health-related quality of life of elderly living in the rural community and homes for the elderly in a district of India. Application of the short form 36 (SF-36) health survey questionnaire. Z Gerontol Geriatr. 2010;43(4):259-63.

14. Heepkaew S. Quality of life of patients with type II diabetes mellitus in Kuchinara District, Kalasin Province. Res Develop Health Sys J. 2011:4(1):22-36.

15. Solli O, Stavem K, Kristiansen IS. Health-related quality of life in diabetes: The associations of complications with EQ-5D scores. Health Qual Life Outcomes. 2010;8:18

16. Zhang $P$, Brown MB, Bilik D, Ackermann RT, Li R, Herman WH. Health utility scores for people with type 2 diabetes in U.S. managed care health plans: Results from Translating Research Into Action for Diabetes (TRIAD). Diabetes Care. 2012;35(11):2250-6.

17. Hayes A, Arima H, Woodward M, Chalmers J, Poulter N, Hamet P. Changes in Quality of Life Associated with Complications of Diabetes: Results from the ADVANCE Study. Value in Health. 2016;19(1):36-41.

18. Gebremedhin T, Workicho A, Angaw DA. Health-related quality of life and its associated factors among adult patients with type II diabetes attending Mizan Tepi University Teaching Hospital, Southwest Ethiopia. BMJ Open Diabetes Res Care. 2019;7(1):e000577. doi: 10.1136/bmjdrc-2018-000577.

19. Andrade CS, Ribeiro GS, Santos CAST, Silva NRCSN, Moreira ED. Factors associated with high levels of glycated haemoglobin in patients with type 1 diabetes: A multicentre study in Brazil. BMJ Open. 2017;7(12):e018094.

20. Jin J, Sklar GE, Oh VMS, Li SC. Factors affecting therapeutic compliance: A review from the patient's perspective. Ther Clin Risk Manag. 2008;4(1):269-86.

21. Kanglee K. Factors Associated With Glycemic Control Among People with Type 2 Diabetes Mellitus at Phramongkutklao Hospital, Bangkok. J Royal Thai Army Nurses. 2014; 15(3):256-68.

22. Yang $S$, Kong W, Hsue $C$, Fish AF, Chen $Y$, Guo $X$, et al. Knowledge of A1c Predicts Diabetes Self-Management and A1c Level among Chinese Patients with Type 2 Diabetes. PLoS One. 2016;11(3):e0150753.

23. Roy S, Sherman A, Monari-Sparks MJ, Schweiker O, Jain N, Sims E, et al. Association of Comorbid and Metabolic Factors with Optimal Control of Type 2 Diabetes Mellitus. N Am J Med Sci. 2016;8(1):31-9.

24. Ahmad NS, Islahudin F, Paraidathathu T. Factors associated with good glycemic control among patients with type 2 diabetes mellitus. J Diabetes Investig. 2014;5(5):563-9.

25. Tinsley LJ, Kupelian V, D'Eon SA, Pober D, Sun JK, King GL, et al. Association of Glycemic Control With Reduced Risk for Large-Vessel Disease After More Than 50 Years of Type 1 Diabetes. J Clin Endocrinol Metab. 2017;102(10):3704-11.

Article History: Submission Date : 07-04-2020; Revised Date : 26-04-2020; Acceptance Date : 06-06-2020

Cite this article: Khanthaboon P, Kumbudda T, Poonsuk P, Taengthonglang C, Saramunee K, Phimarn W. Factors Associated with Quality of Life and Glycemic Control in Diabetes Mellitus Type 2 Patients in Sangkha Hospital, Surin Province, Thailand. J Young Pharm. 2020;12(2):149-52. 